\title{
Electrophysiologic and mechanical evidence of superiority of hyperpolarizing versus depolarizing cardioplegia in protection of endothelium-derived hyperpolarizing factor- mediated endothelial function: A study in coronary resistance arteries
}

Guo-Wei He, MD, PhD, DSc ${ }^{a, b, c}$

Zhi-Dong Ge, MD, PhD*

Anthony P. C. Yim, MDa

Qin Yang, MD, PhD ${ }^{\mathrm{a}, \mathrm{c}}$

Rong-Zheng Zhang, $\mathrm{MD}^{\mathrm{a}}$

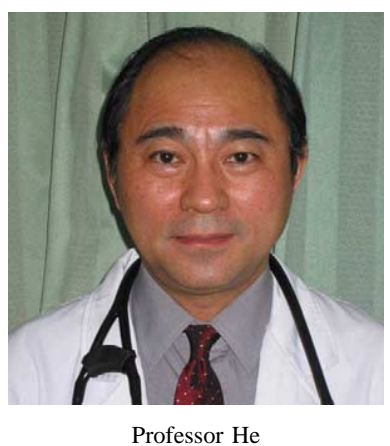

From the Division of Cardiothoracic Surgery, Department of Surgery, The Chinese University of Hong Kong, ${ }^{a}$ Hong Kong, China, the Wuhan Heart Institute, Wuhan

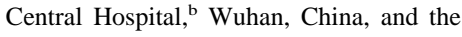
Providence Heart Institute, ${ }^{c}$ Albert Starr Academic Center, Department of Surgery, Oregon Health and Science University, Portland, Ore.

Supported by Hong Kong Research Grants Council grants CUHK4127/01M, CUHK4383/03M and CUHK direct grant 2002.1.108, and the Providence St Vincent Medical Foundation, Portland, Ore.

Received for publication May 14, 2003; revisions received Aug 24, 2003; accepted for publication Sept 29, 2003.

Address for reprints: Professor Guo-Wei $\mathrm{He}, \mathrm{MD}, \mathrm{PhD}$, DSc, Department of Surgery, The Chinese University of Hong Kong, Block B, 5A, Prince of Wales Hospital, Shatin, NT, Hong Kong (E-mail: gwhe@surgery.cuhk.edu.hk).

${ }^{*} \mathrm{Dr} \mathrm{Ge}$ is currently affiliated with the Medical College of Wisconsin, Madison, Wis.

J Thorac Cardiovasc Surg 2004;127: 1773-80

$0022-5223 / \$ 30.00$

Copyright ( $\odot 2004$ by The American Association for Thoracic Surgery

doi:10.1016/j.jtcvs.2003.09.051
Objective: The advantages of hyperpolarizing cardioplegia with potassium-channel openers versus depolarizing cardioplegia have been suggested but not demonstrated in coronary microarteries. This study examined the simultaneous electric and tonic alteration of coronary microarteries at the cellular level during and after exposure to depolarizing cardioplegia or hyperpolarizing cardioplegia, with emphasis on endothelium-derived hyperpolarizing factor-mediated relaxation and hyperpolarization.

Methods: Porcine coronary microarteries (diameter, approximately 200-400 $\mu \mathrm{m}$ ) were incubated with depolarizing cardioplegia $(20 \mathrm{mmol} / \mathrm{L} \mathrm{KCl})$ or hyperpolarizing cardioplegia ( $10 \mu \mathrm{mol} / \mathrm{L}$ aprikalim) for 1 hour. Cellular membrane potential with a glass microelectrode in a coronary smooth muscle cell and isometric force of the muscle were simultaneously measured in a myograph.

Results: Depolarizing cardioplegia incubation produced a stable contraction (from $4.9 \pm 0.3 \mathrm{mN}$ to $7.3 \pm 0.4 \mathrm{mN}$ ) and depolarization (from $-51 \pm 1 \mathrm{mV}$ to $-41 \pm$ $2 \mathrm{mV}$ ). In contrast, hyperpolarizing cardioplegia relaxed (from $4.8 \pm 0.3 \mathrm{mN}$ to 3.5 $\pm 0.3 \mathrm{mN}$ ) and hyperpolarized (from $-51 \pm 2 \mathrm{mV}$ to $-56 \pm 1 \mathrm{mV}$ ) the smooth muscle. After exposure to depolarizing cardioplegia, the bradykinin-induced, endothelium-derived hyperpolarizing factor-mediated relaxation reduced from $66.2 \% \pm$ $5.0 \%$ to $18.4 \% \pm 3.7 \%(P<.001)$, and the membrane hyperpolarization reduced from $18 \pm 1 \mathrm{mV}$ to $7 \pm 1 \mathrm{mV}(P<.001)$ in the presence of indomethacin and $\mathrm{N}^{\mathrm{G}}$-nitro-L-arginine. In contrast, hyperpolarizing cardioplegia did not affect the bradykinin-induced responses.

Conclusions: In the coronary microarteries, exposure to hyperpolarizing cardioplegia preserves whereas depolarizing cardioplegia reduces the endothelium-derived hyperpolarizing factor-mediated electric (hyperpolarization) and mechanical (relaxation) responses. Thus hyperpolarizing cardioplegia is superior to depolarizing cardioplegia in protecting the endothelial function in the coronary microcirculation.

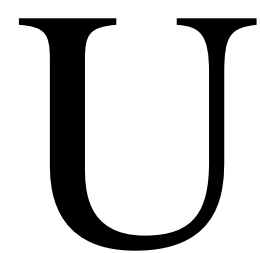

se of depolarizing cardioplegia (DC) is the most common method for myocardial preservation in cardiac surgery. ${ }^{1}$ Potassium $\left(\mathrm{K}^{+}\right)$ at high concentrations (hyperkalemia, usually containing 10-20 $\mathrm{mmol} / \mathrm{L} \mathrm{K}^{+}$) is the major depolarizing agent in cardioplegia. Despite the cardioprotective effect, DC causes depolarization of the membrane potential by means of extracellular hyperkalemia, resulting in energy storage depletion and calcium overload, ${ }^{2}$ ongoing cellular 
metabolic processes and derangements in transmembrane ionic gradients, ${ }^{2}$ influx of sodium through the sodium "window current," exchange of intracellular sodium for calcium through the sodium-calcium exchange, influx of calcium through the calcium window current, ${ }^{3}$ and leakage of calcium from the sarcoplasmic reticulum. These factors contribute to myocardial calcium overload, which is related to myocardial injury during the arrest, ${ }^{4}$ with clinical evidence of ventricular dysfunction. ${ }^{3-5}$ Moreover, DC has deleterious effects on coronary endothelium ${ }^{6,7}$ and might cause coronary vasospasm, ${ }^{8,9}$ leading to suboptimal myocardial recovery after cardiac surgery.

Because of these considerations, hyperpolarizing cardioplegia (HC) has been proposed for cardiac arrest during cardiac surgery. ${ }^{10-12}$ The natural resting state of the cardiac myocyte is at hyperpolarized membrane potentials. ${ }^{10} \mathrm{Few}$ channels or pumps are activated at hyperpolarized potentials, and there is little metabolic demand on the ventricular myocyte at this status.

Potassium-channel openers (KCOs) have been suggested to be used for cardioprotection. ${ }^{10-15}$ Adenosine triphosphate (ATP)-sensitive potassium-channel openers inhibit the development of myocardial contracture, reduce the release of lactate dehydrogenase, and preserve intracellular ATP content during ischemia. ${ }^{16}$ Because of the hyperpolarizing effect of KCOs on the membrane potential of myocytes, cardioplegia with KCOs has been defined as $\mathrm{HC}^{12}$ and has significantly prolonged the period to the development of myocardial contracture ${ }^{12,14}$ and afforded a significantly better postischemic recovery of function than DC arrest. ${ }^{12}$ In addition, KCOs hyperpolarize the membrane potential of the smooth muscle, subsequently affecting voltage-operated calcium channels and intracellular calcium release, and relax the vessel ${ }^{16,17}$ that obviously facilitates the myocardial perfusion.

Endothelium-dependent relaxation is known to be due to nitric oxide (NO), prostacyclin, and endothelium-derived hyperpolarizing factor (EDHF). The nature of EDHF has not been finally identified, although many substances, such as epoxyeicosatrienoic acid, anadamide, $\mathrm{K}^{+}, \mathrm{H}_{2} \mathrm{O}_{2}$, citrulline, $\mathrm{NH}_{3}$, and ATP have been suggested to be the candidates for EDHF. ${ }^{18}$ EDHF induces vascular smooth muscle relaxation through hyperpolarization of the smooth muscle cells, ${ }^{18-20}$ which might involve $\mathrm{K}^{+}$channels. ${ }^{19,21}$ In contrast, NO mainly relaxes blood vessels through the cyclic guanosine monophosphate pathway. ${ }^{22}$

Our previous studies have demonstrated that in large conductance coronary arteries, DC (hyperkalemia, 20-50 $\mathrm{mmol} / \mathrm{L} \mathrm{K}^{+}$), but not $\mathrm{HC}$, reduces the EDHF-mediated relaxation. The present study was designed to examine (1) the effect of $\mathrm{HC}$ versus DC in the coronary resistance arteries (microarteries) and (2) the relaxation-associated electrophysiologic changes of the cellular membrane potential in the microartery.

\section{Methods}

Preparation and Mounting of Coronary Microarteries Fresh porcine hearts collected from a local slaughterhouse were placed in a container filled with cold Krebs' solution and immediately transferred to the laboratory. On receipt of the hearts, the intramyocardial coronary arteries (usually the tertiary branches of the left anterior descending artery) were carefully dissected in Krebs' solution under a microscope, with great care taken to protect the endothelium. These are proximal resistance arteries (microarteries). The vessel was cleaned of fat and connective tissue and cut into 2 cylindrical rings under a microscope, each of which was $2 \mathrm{~mm}$ long. A suitable length of stainless-steel wire (40 $\mu \mathrm{m}$ in diameter) was guided through the lumen of each ring. The wire was fixed tightly on a jaw in a 2-channel myograph (model 500A; J. P. Trading, Aarhus, Denmark), and another wire was passed lightly through the lumen and then anchored to the other jaw of the same chamber. These 2 wires were attached to either a force transducer or a micrometer. A calibrated force transducer was used to measure the force, with the output shown on a computer screen, and the graphs were printed on a printer. Data were digitized and stored in the computer. Two organ-chamber arrangements were run concurrently.

The Krebs solution was aerated with a gas mixture of $95 \%$ $\mathrm{O}_{2}-5 \% \mathrm{CO}_{2}$ at $37^{\circ} \mathrm{C} \pm 0.1{ }^{\circ} \mathrm{C}$ and had the following composition: $\mathrm{NaCl}, 118.4 \mathrm{mmol} / \mathrm{L} ; \mathrm{KCl}, 4.7 \mathrm{mmol} / \mathrm{L} ; \mathrm{MgSO}_{4} .7 \mathrm{H}_{2} \mathrm{O}, 1.2$ $\mathrm{mmol} / \mathrm{L} ; \mathrm{KH}_{2} \mathrm{PO}_{4}, 1.2 \mathrm{mmol} / \mathrm{L} ; \mathrm{NaHCO}_{3}, 25 \mathrm{mmol} / \mathrm{L} ;(+)$-glucose, $11.1 \mathrm{mmol} / \mathrm{L}$; and $\mathrm{CaCl}_{2} \cdot 2 \mathrm{H}_{2} \mathrm{O}, 2.5 \mathrm{mmol} / \mathrm{L}$. This gives the following final molar concentration: $\mathrm{Na}^{+}, 143.4 \mathrm{mmol} / \mathrm{L} ; \mathrm{K}^{+}, 5.9$ $\mathrm{mmol} / \mathrm{L} ; \mathrm{Ca}^{2+}, 2.5 \mathrm{mmol} / \mathrm{L} ; \mathrm{Mg}^{2+}, 1.2 \mathrm{mmol} / \mathrm{L} ; \mathrm{Cl}^{-}, 128.7$ $\mathrm{mmol} / \mathrm{L} ; \mathrm{HCO}_{3}{ }^{-}, 25 \mathrm{mmol} / \mathrm{L} ; \mathrm{SO}_{4}{ }^{2-} 1.2 \mathrm{mmol} / \mathrm{L} ; \mathrm{H}_{2} \mathrm{PO}_{4}{ }^{-}, 1.2$ $\mathrm{mmol} / \mathrm{L}$; and glucose, $11.1 \mathrm{mmol} / \mathrm{L}$.

\section{Normalization}

A previously described method ${ }^{23}$ was used to normalize vascular rings under a pressure simulating the conditions encountered in the coronary microarteries at their normal transmural pressure according to their own length-tension curves. After equilibration at $37^{\circ} \mathrm{C}$ $\pm 0.1^{\circ} \mathrm{C}$ for 30 minutes, the arterial rings were progressively stretched until the passive transmural pressure reached $100 \mathrm{~mm}$ $\mathrm{Hg}$, and the pressure was then immediately released. The internal circumference was then set to a normalized value estimated to be equivalent to $90 \%$ of the circumference at a passive transmural pressure of $100 \mathrm{~mm} \mathrm{Hg}$ throughout the experiment. The isometric force at this setting is the passive, or resting, force in the absence of contraction tone that is similar to a physiologic pressure, and this has been shown to allow maximum tension development. Only arterial rings of 200 to $400 \mu \mathrm{mol} / \mathrm{L}$ in internal diameter at the transmural pressure of $100 \mathrm{~mm} \mathrm{Hg}$ were used in this study.

\section{Simultaneous Measurement of Isometric Force and Membrane Potential}

The myograph was placed in a metal screen cage (Farady cage). The arterial rings were mounted on the myograph and normalized as mentioned above. A conventional glass microelectrode filled with $3 \mathrm{~mol} / \mathrm{L} \mathrm{KCl}$ (tip resistance, 100-120 M ) was advanced by 
using a pipette holder mounted on a 3-dimensional vernier-type hydraulic micromanipulator and inserted into a single smooth muscle cell from the adventitial surface of the rings. This setting allows simultaneous measurement of isometric force and the membrane potential contributing to this force production. ${ }^{19,24}$ The electrical signals were amplified by means of a battery-operated, low-noise, wide-band electrometer preamplifier (World Precision Instruments, New Haven, Conn). The membrane potential was monitored continuously on a dual-trace oscilloscope (Maxtec International Corporation, Chicago, Ill) and simultaneously recorded in a computer. The following criteria were used to assess the validity of a successful impalement into a cell: (1) a sudden negative shift in voltage, followed by (2) a stable negative voltage for more than 2 minutes and (3) an instantaneous return to the previous voltage level on dislodgement of the microelectrode. ${ }^{19,24}$ The recording of the membrane potential was taken simultaneously with the recording of force changes by using the myograph recording system.

\section{Protocol}

After normalization, the rings were equilibrated for 30 minutes and incubated with Krebs solution (control), with the HC containing 10 $\mu \mathrm{mol} / \mathrm{L}$ aprikalim or DC containing $20 \mathrm{mmol} / \mathrm{L} \mathrm{K}^{+}$(replacement of $\mathrm{Na}^{+}$with $20 \mathrm{mmol} / \mathrm{L} \mathrm{K}^{+}$in Krebs solution). After incubation at $37^{\circ} \mathrm{C} \pm 0.1^{\circ} \mathrm{C}$ for 60 minutes, the rings were repeatedly washed with normal Krebs solution and equilibrated for 30 minutes. Indomethacin (a cyclooxygenase inhibitor, $7 \mu \mathrm{mol} / \mathrm{L}$ ) and $\mathrm{N}^{\mathrm{G}}$-nitroL-argine (L-NNA; an inhibitor of NO synthase, $300 \mu \mathrm{mol} / \mathrm{L}$ ) were added into the solution in the myograph chambers for 30 minutes to inhibit the production of prostacyclin and NO. The rings were contracted with the thromboxane $\mathrm{A}_{2}$ mimetic U46619 (3 $\left.\mu \mathrm{mol} / \mathrm{L}\right)$. When stable contractions and depolarization to U46619 were reached, bradykinin was cumulatively added to establish concentration-response curves.

Simultaneous recording of bradykinin-induced hyperpolarization and relaxation in coronary microarteries: Group $1(n=$ 7-10 in each subgroup). The isometric force and membrane potential of coronary smooth muscle cells were simultaneously measured during the period of incubation with DC or HC, equilibration after washout with Krebs solution, contraction with the U46619, and relaxation with bradykinin at the concentrations of -10 to -7 $\log \mathrm{mol} / \mathrm{L}$, with $1 \log$ unit increments. A total of 26 arterial rings successfully completed all abovementioned simultaneous measurements of membrane potential, and isometric forces were analyzed. Among them, 7 rings were treated with $\mathrm{HC}, 9$ with DC, and 10 were used for control purposes. The rings were excluded from data analysis if we were unable to simultaneously measure the relaxation and hyperpolarization induced by cumulative addition of bradykinin $(0.1 \mathrm{nmol} / \mathrm{L}$ to $0.1 \mu \mathrm{mol} / \mathrm{L})$ because of either unsuccessful implementation of the electrode or unsuccessful maintenance of the electrode intracellularly for the whole period of the dose-response curves for bradykinin. Only one concentration-response (relaxation or repolarization-hyperpolarization) curve was established from each coronary ring. From 7 to 10 rings in each group, a mean concentration-response curve was established.

Full concentration-relaxation curves for bradykinin after exposure to HC or DC compared with control rings: Group $2(n=$
7 in each subgroup). In this group of experiments, each coronary microartery contributed to 2 rings. One was used as a control, and the other was incubated with either HC or DC for 1 hour, as in group 1. Therefore in this group each ring treated with either $\mathrm{HC}$ or DC had its own control ring taken from the same microartery. Bradykinin-induced relaxation in the U46619 precontraction was established with concentrations of -10 to $-6.5 \mathrm{log} \mathrm{mol} / \mathrm{L}$ in half-log unit increments in each ring. The group data were from 7 rings.

\section{Data Analysis}

Relaxation was expressed as the percentage of decrease in isometric force induced by U46619. Hyperpolarization (repolarization) was reported as the reduced amplitude of the membrane potential (depolarization) with U46619. The mean maximal relaxation for each group was calculated from group data. The effective concentration of bradykinin that caused $50 \%$ of maximal relaxation was defined as the $\mathrm{EC}_{50}$. The $\mathrm{EC}_{50}$ was determined from each concentration-relaxation curve by using a logistic, curve-fitting equation:

$$
\mathrm{E}=\mathrm{MA}^{\mathrm{p}} /\left(\mathrm{A}^{\mathrm{p}}+\mathrm{K}^{\mathrm{p}}\right),
$$

where $\mathrm{E}$ is response, $\mathrm{M}$ is maximal relaxation, $\mathrm{A}$ is concentration, $\mathrm{K}$ is $\mathrm{EC}_{50}$ concentration, and $\mathrm{P}$ is the slope parameter. ${ }^{20,23}$ From this fitted equation, the mean $\mathrm{EC}_{50}$ value was calculated from each group.

Data are expressed as means \pm 1 SEM for $n$ observations, where $n$ equals the number of coronary arterial rings. The data were analyzed with paired and unpaired $t$ tests and analysis of variance (followed by the Scheffe F test) when appropriate.

\section{Drugs}

Drugs used and their sources were as follows: bradykinin, L-NNA, and indomethacin were from Sigma chemical Co, St Louis, Mo. Aprikalim was a gift from Rhône-Poulenc Rover, Centre De Recherche de Vitry-alfortrille, France. U46619 was from Cayman Chemical, Ann Arbor, Mich. L-NNA (dissolved in distilled water) and indomethacin (dissolved in ethanol) were stored at $4^{\circ} \mathrm{C}$. The solution of U46619 was held frozen until required.

\section{Results}

\section{Baseline Characteristics of Coronary Microarteries}

The internal diameter of the coronary microarteries at a transmural pressure of $100 \mathrm{~mm} \mathrm{Hg}$ was $349 \pm 11 \mu \mathrm{mol} / \mathrm{L}$ $(\mathrm{n}=10)$ in the control group, $349 \pm 10 \mu \mathrm{mol} / \mathrm{L}(\mathrm{n}=9)$ in the DC group, and $345 \pm 13 \mu \mathrm{mol} / \mathrm{L}(\mathrm{n}=7)$ in the $\mathrm{HC}$ group $(P>.05)$. After normalization, the resting force of vascular rings was $4.8 \pm 0.3 \mathrm{mN}$ in the control group, 4.9 $\pm 0.4 \mathrm{mN}$ in the DC group, and $4.7 \pm 0.2 \mathrm{mN}$ in the $\mathrm{HC}$ group $(P>.05)$. The resting membrane potential of coronary smooth muscle cells was $-52 \pm 2 \mathrm{mV}$ in the control group, $-52 \pm 2 \mathrm{mV}$ in the DC group, and $-51 \pm 1 \mathrm{mV}$ in the HC group $(P>.05)$. There were no significant differences $(P>.05)$ in the internal diameters, resting tones, and resting membrane potentials among the 3 groups. 

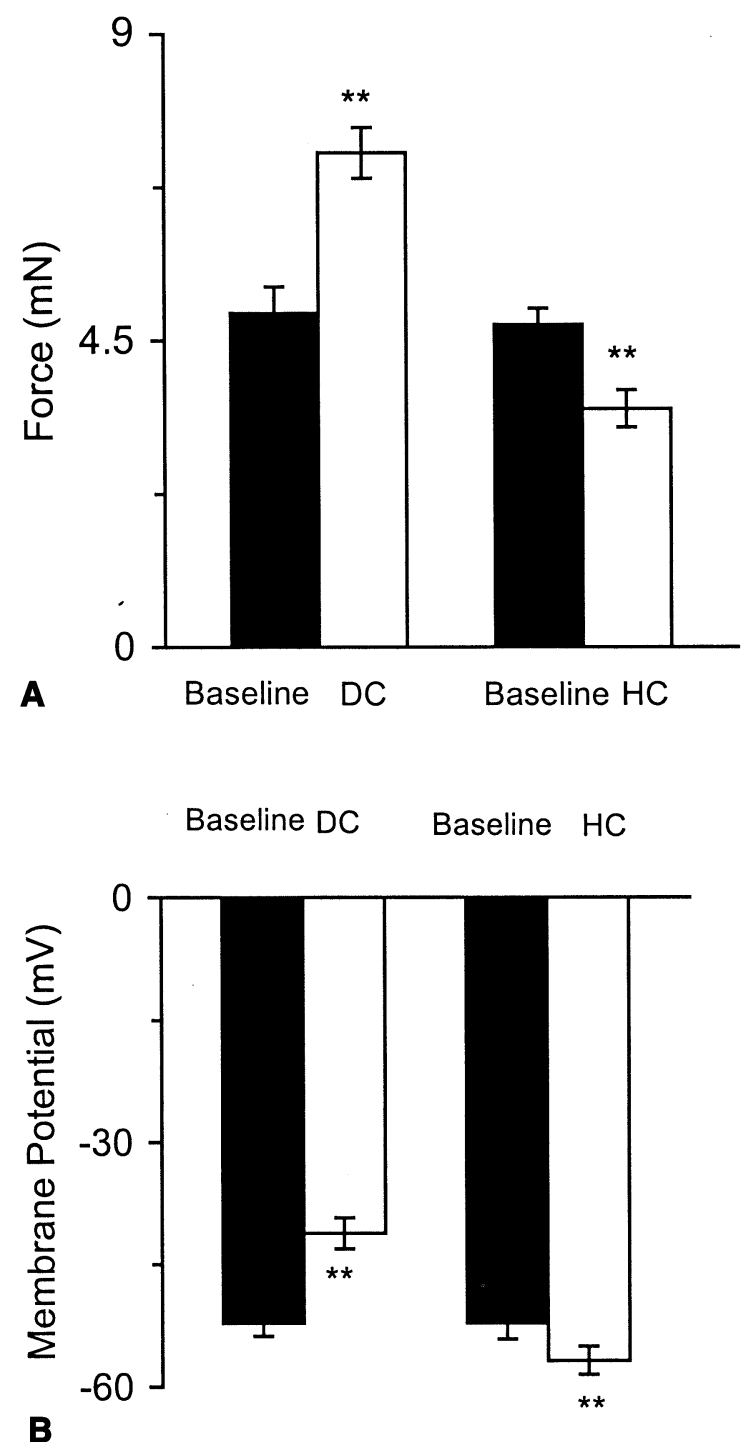

Figure 1. Isometric force (A) and associated membrane potential (B) of coronary microarteries during incubation with DC and HC. Values are means \pm 1 SEM. ${ }^{*} P<.05,{ }^{* *} P<.01$, and ${ }^{* * *} P<.001$ compared with the control.

Tonic and Electric Alteration of Coronary Microarteries During Exposure to DC and $\mathrm{HC}$ and After Washout

Addition of DC with $20 \mathrm{mmol} / \mathrm{L} \mathrm{KCl}$ induced a contraction of coronary microarteries $(7.3 \pm 0.4 \mathrm{mN}, \mathrm{n}=9, P=.001$ vs the resting tone), and the membrane potential was depolarized to $-41 \pm 2 \mathrm{mV}(P=.002$ vs the resting membrane potential, Figure 1).

Incubation with HC produced a rapid and stable relaxation of coronary rings. The reduction in force caused by $\mathrm{HC}$ was associated with a change in membrane hyperpolarization (Figure 1). When the relaxation reached a sustained plateau, the force and membrane potential simultaneously recorded were $3.5 \pm 0.3 \mathrm{mN}(\mathrm{n}=7, P=.007$ vs the resting tone $)$ and $-56 \pm 1 \mathrm{mV}(P=.03$ vs the resting membrane potential), respectively.

At 30 minutes after washout, there were no significant differences in isometric force and membrane potential of coronary smooth muscle cells between the HC or DC groups and the control group $(P>.05)$.

\section{U46619-Induced Contraction and Depolarization}

After coronary rings were incubated with indomethacin and L-NNA for 30 minutes, addition of $3 \mathrm{nmol} / \mathrm{L}$ U46619 produced a stable and rapidly developing contraction in the HC, DC, and control groups. Simultaneously, a depolarization was recorded. The U46619-induced contraction force and associated membrane potential were $7.5 \pm 0.5 \mathrm{mN}$ and $-27.6 \pm 2 \mathrm{mV}$ in the control group, $7.8 \pm 0.8 \mathrm{mN}$ and $-27.5 \pm 2.1 \mathrm{mV}$ in the DC group, and $7.1 \pm 0.8 \mathrm{mN}$ and $-25.9 \pm 3.3 \mathrm{mV}$ in the $\mathrm{HC}$ group, respectively. No differences existed among the 3 groups in the U46619-induced contraction forces $(P=.6)$ and membrane potentials $(P=$ .7 , analysis of variance).

\section{Simultaneous Recording of Bradykinin-Induced Relaxation and Hyperpolarization in Coronary Microarteries (Group 1)}

In the presence of indomethacin and L-NNA, when U46619induced contraction reached a stable plateau, cumulative addition of -10 to $-7 \log \mathrm{mol} / \mathrm{L}$ bradykinin $(0.1 \mathrm{nmol} / \mathrm{L}$ to $0.1 \mu \mathrm{mol} / \mathrm{L}$ ) induced a simultaneous relaxation and hyperpolarization of coronary microarteries in a concentrationdependent manner (Figure 2). In the control rings the bradykinin-induced maximal relaxation and associated hyperpolarization were $68.0 \% \pm 4.9 \%$ and $18 \pm 1 \mathrm{mV}(\mathrm{n}=$ $10)$, respectively. HC treatment $(n=7)$ did not affect the bradykinin-induced relaxation and associated membrane hyperpolarization (Figure 2, A). However, DC treatment significantly reduced the bradykinin-induced relaxation and hyperpolarization at the concentrations of -9 to $-7 \log$ $\mathrm{mol} / \mathrm{L}(1 \mathrm{nmol} / \mathrm{L}$ to $0.1 \mu \mathrm{mol} / \mathrm{L}$; Figure $2, B)$. The maximal relaxation and hyperpolarization decreased to $18.4 \% \pm$ $3.7 \%$ and $9.0 \pm 1.0 \mathrm{mV}(\mathrm{n}=9, P<.001)$, respectively. Figure 3 shows the group data.

\section{Concentration-Relaxation Curves for Bradykinin After Exposure to HC or DC Compared With Control Rings: Group 2}

The concentration-relaxation curves for bradykinin in the rings treated with $\mathrm{HC}$ or DC for 1 hour compared with their own control rings treated with Krebs solution are shown in Figure 4. Similar to group 1, in which simultaneous measurement of isometric force and membrane potential was performed, the concentration-dependent relaxation induced by bradykinin was not altered by $\mathrm{HC}$ but was reduced by 

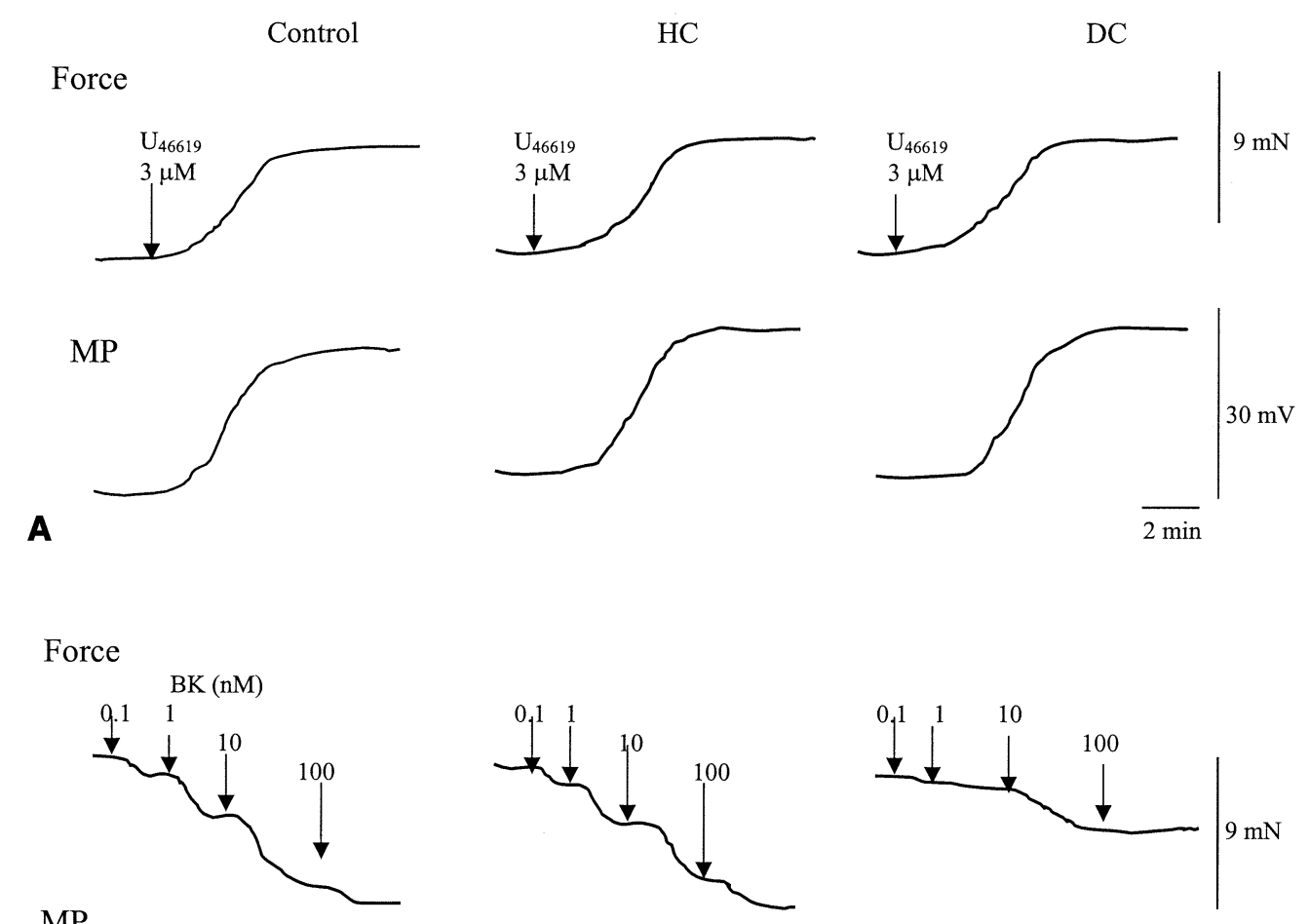

MP
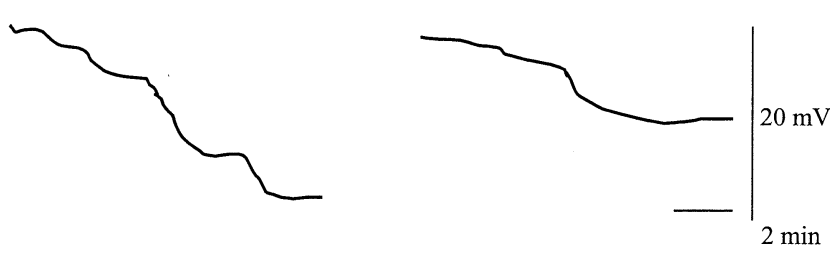

Figure 2. Trace recording of simultaneous measurement of U46619-induced precontraction (force) and depolarization (MP; A) and bradykinin (BK)-induced relaxation (force) and membrane hyperpolarization (B) of coronary microarteries in the presence of indomethacin $(7 \mu \mathrm{mol} / \mathrm{L})$ and $\mathrm{L}-\mathrm{NNA}(300 \mu \mathrm{mol} / \mathrm{L})$.

DC at concentrations of -9 to $-6.5 \log \mathrm{mol} / \mathrm{L}(1-316$ $\mathrm{nmol} / \mathrm{L})$. The maximal relaxation was reduced from $69.3 \%$ $\pm 3.2 \%(\mathrm{n}=7)$ to $11.3 \% \pm 2.4 \%(\mathrm{n}=7, P<.001)$. In the control group the $\mathrm{EC}_{50}$ for bradykinin was $21.3 \pm 6.9$ $\mathrm{nmol} / \mathrm{L}(\mathrm{n}=7)$. HC $(13.7 \pm 4.4 \mathrm{nmol} / \mathrm{L})$ or DC $(16.4 \pm 5.1$ $\mathrm{nmol} / \mathrm{L})$ treatment did not affect the $\mathrm{EC}_{50}$ value for bradykinin $(P>.05)$.

\section{Discussion}

The present study, done at the cellular level, has demonstrated in the porcine coronary microarteries that (1) HC with the KCO aprikalim hyperpolarizes and relaxes the coronary microartery and preserves the EDHF-mediated hyperpolarization and relaxation and (2) DC with 20 $\mathrm{mmol} / \mathrm{L} \mathrm{KCl}$ contracts and depolarizes the coronary smooth muscle cells and reduces the EDHF-mediated hyperpolarization and associated relaxation. Therefore the present study suggests that $\mathrm{HC}$ is superior to $\mathrm{DC}$ regarding protec- tion of the EDHF-mediated function in coronary microarteries.

\section{Electrical and Mechanical Changes of Coronary} Microarteries During Incubation to Cardioplegia In the present study incubation with DC $(20 \mathrm{mmol} / \mathrm{L} \mathrm{KCl})$ induced a stable contraction of coronary microarteries and sustained depolarization of smooth muscle cells. This is consistent with those obtained in cardiac myocytes ${ }^{25}$ and in large coronary conduit arteries. ${ }^{6}$ Although there is no direct evidence concerning how continuous depolarization affects the transmembrane ion gradients in this vasculature, the progressive depolarization of cardiac myocytes through extracellular hyperkalemia has been shown to produce an intracellular accumulation of sodium, calcium, and chloride ions. ${ }^{26}$ The derangements in these transmembrane ionic gradients lead to the activation of relevant ionic pumps at a considerable energy cost. ${ }^{26}$ Therefore the ongoing depolar- 

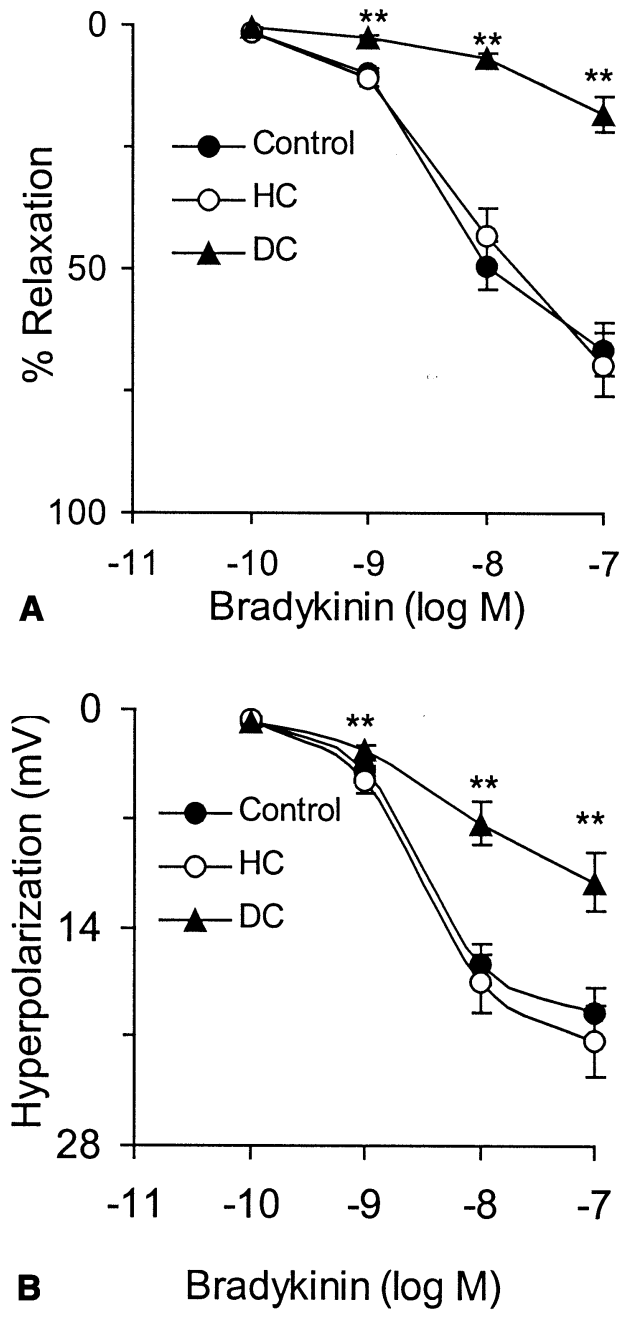

Figure 3. Simultaneous measurement of bradykinin-induced relaxation in $1 \log$ unit increments $(A)$ and membrane hyperpolarization (B) of coronary microarteries precontracted with U46619 in the presence of indomethacin (7 $\mu \mathrm{mol} / \mathrm{L})$ and L-NNA (300 $\mu \mathrm{mol} / \mathrm{L})$ in the control rings $(n=10)$ and in rings treated with $\mathrm{HC}$ $(n=9)$ or $D C(n=7)$. Values are presented as means \pm 1 SEM. ${ }^{*} P<.05,{ }^{* *} P<.01$, and ${ }^{*}{ }^{*} P<.001$ compared with the control.

ization by DC undoubtedly produces unfavorable effects on coronary microarteries.

In contrast, the incubation of $\mathrm{HC}$ containing aprikalim results in vasodilation and membrane hyperpolarization in the coronary microarteries. Aprikalim is a potent agent that selectively opens ATP-sensitive potassium-channels. ${ }^{16,17,27}$ In the blood vessel ${ }^{28}$ and in the cardiac myocyte, ${ }^{29}$ the opening of ATP-sensitive potassium-channels leads to the outward current of $\mathrm{K}^{+}$and membrane hyperpolarization, and therefore incubation of $\mathrm{HC}$ containing aprikalim leads to membrane hyperpolarization of vascular smooth muscle cells in the coronary microarteries.

\section{Alteration of EDHF-Mediated Function in Coronary Microarteries After Exposure to Cardioplegia}

As mentioned above, the endothelial cells release at least 3 relaxing mediators: NO, prostacyclin, and EDHF. Although the chemical nature of EDHF remains unidentified, it is known that this factor relaxes the smooth muscle cell through electrical response (hyperpolarization) associated with mechanical response (relaxation). The mechanism of EDHF to relax the smooth muscle cell is therefore similar to hyperpolarizing agents, such as KCOs, that can be used as cardioplegia. In a previous study we demonstrated that $\mathrm{HC}$ is superior to DC on the protection of the EDHF-mediated relaxation in large coronary arteries. The present study was designed to answer 2 further questions. First, the microcirculation in the coronary system accounts for at least $50 \%$ of the total resistance. Therefore we asked whether the use of $\mathrm{HC}$ or DC affects the endothelial function in the coronary microcirocirculation. Second, regarding the mechanism of the effect of cardioplegia on the endothelial function, the only way to demonstrate the endothelium-smooth muscle interaction through the EDHF pathway is to simultaneously measure the electrical and mechanical responses in the coronary microartery, but this has never been reported. In particular, it is technically very difficult to simultaneously measure the membrane potential of the smooth muscle cell and the contraction-relaxation of the smooth muscle in the microartery. In the present study we successfully measured these 2 simultaneous parameters and clearly demonstrated that the reduction of the EDHF-mediated relaxation in the coronary microartery is associated with simultaneous reduction of the cellular membrane hyperpolarization. Therefore the present study, for the first time, demonstrates the mechanism of the superiority of hyperpolarizing agents to depolarizing agents on the endothelial function.

$\mathrm{NO}$ and EDHF are the 2 major mediators for the endothelium-dependent relaxation in the coronary artery. ${ }^{19,20}$ The present study has focused on the EDHF pathway and investigated the effect of cardioplegia on the coronary microarterial endothelium, excluding the effect of ischemia and reperfusion, to provide information on the composition of cardioplegia. The effect of cardioplegia on NO production and the combined effect with ischemia and reperfusion are to be clarified.

\section{Limitations of the Study}

The present study investigated the effect of HC or DC as crystalloid cardioplegia on a specific endothelium-derived factor: EDHF-mediated function. The study was performed in vitro. Although this is the best way to study the cellular mechanisms (eg, membrane potential measurement), the results cannot be directly transferred to the clinical setting. Blood cardioplegia is now the well-accepted standard 


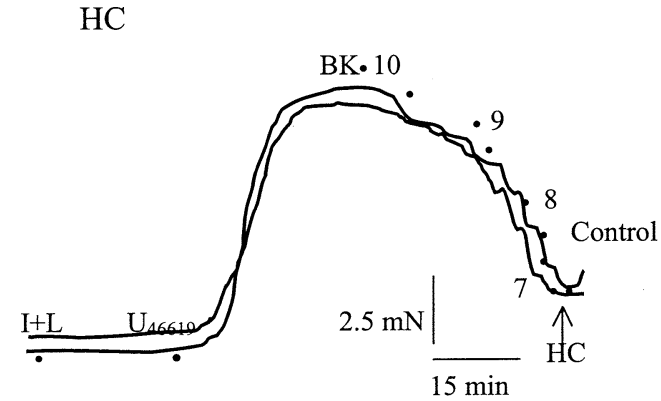

A

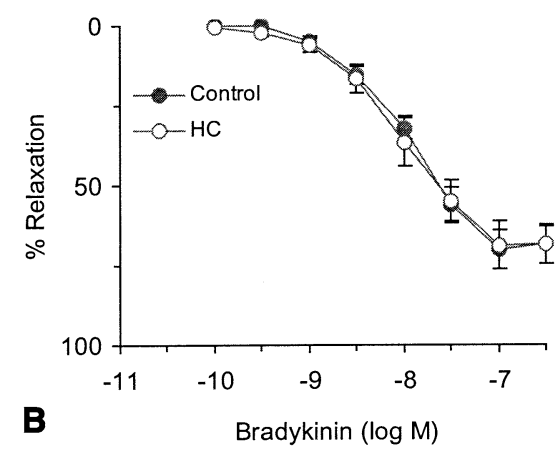

DC
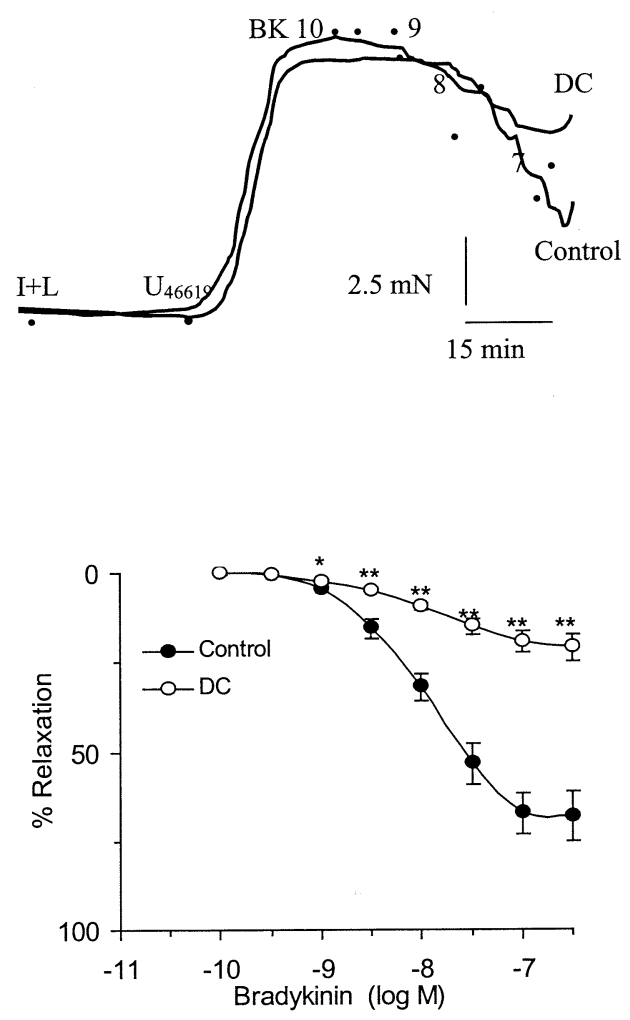

Figure 4. Full bradykinin (BK)-induced relaxation in half log unit increments compared with the rings taken from the same microartery. In this group of experiments, each coronary microartery was cut into 2 rings: one was allocated to the control group and the other was treated with either $\mathrm{HC}(\mathrm{n}=7)$ or $\mathrm{DC}(\mathrm{n}=7)$. A, Trace recording from 2 rings originating from the same microartery treated with $\mathrm{HC}$ or Krebs solution (control, left panel) or with DC or Krebs solution (control, right pane); B, group data ( $n=7$ in each subgroup). Values are presented as means \pm 1 SEM. ${ }^{*} P<.05,{ }^{* *} P<.01$, and ${ }^{* * *} P<.001$ compared with the control.

method for cardioplegia in many cardiac centers because constituents of the blood provide a variety of physiologic protection mechanisms not found in pure crystalloid solutions. The present study therefore should be considered to be a study on a specific mechanism among many factors.

\section{Conclusions}

In the present in vitro study, done at the cellular level, the incubation with depolarizing cardioplegia $(20 \mathrm{mmol} / \mathrm{L} \mathrm{KCl})$ induces contraction and depolarization of porcine coronary microarteries and reduces the subsequent EDHF-mediated hyperpolarization and associated relaxation, even after washout of the cardioplegia. In contrast, incubation with $\mathrm{HC}$ (the KCO aprikalim) simultaneously relaxes and hyperpolarizes the coronary microvascular smooth muscle and preserves the EDHF-mediated function. Thus HC with aprikalim is superior to hyperkalemic DC in the protection of endothelial function in the coronary microartery.

\section{References}

1. Hearse DJ, Braimbridge MV, Jynge P. Protection of the ischemic myocardium: cardioplegia. New York: Raven; 1981.

2. Foglia RP, Steed DL, Follette DM, DeLand E, Buckberg GD. Iatrogenic myocardial edema with potassium cardioplegia. J Thorac Cardiovasc Surg. 1979;78:217-22.

3. Cohen NM, Lederer WJ. Changes in the calcium current of rat heart ventricular myocytes during development. J Physiol (Lond). 1988;406: 115-46.

4. Cooley DA, Reul GJ, Wukasch DC. Ischemic contracture of the heart: "stone heart." Am J Cardiol. 1972;29:575-7.

5. McKenney PA, Apstein CS, Mendes LA, Connelly GP, Aldea GC, Shemin RJ, et al. Increased left ventricular diastolic chamber stiffness immediately after coronary artery bypass surgery. $\mathrm{J} \mathrm{Am} \mathrm{Coll} \mathrm{Cardiol.}$ 1994;24:1189-94.

6. He G-W, Yang C-Q. Superiority of hyperpolarizing to depolarizing cardioplegia in protection of coronary endothelial function. $J$ Thorac Cardiovasc Surg. 1997;114:643-50.

7. Ge Z-D, G-W He. Altered endothelium-derived hyperpolarizing factor-mediated endothelial function in coronary microarteries by St. Thomas' Hospital solution. J Thorac Cardiovasc Surg. 1999;118:173-80.

8. Keller MW, Geddes L, Spotnitz W, Kaul S, Duling BR. Microcirculatory dysfunction following perfusion with hyperkalemic, hypother- 
mic, cardioplegic solutions and blood reperfusion: effects of adenosine. Circulation. 1991;84:2485-94.

9. Sellke FW, Shafique T, Schoen EJ, Weintraub RM. Impaired endothelium-dependent coronary microvascular relaxation following cold potassium cardioplegia and reperfusion. J Thorac Cardiovasc Surg. 1993;105:52-8.

10. Cohen NM, Damiano RJ, Wechsler AS. Is there an alternative to potassium arrest? Ann Thorac Surg. 1995;60:858-63.

11. Maskal SL, Cohen NM, Hsia P-W, Wechsler AS, Damiano RJ. Hyperpolarized cardiac arrest with a potassium-channel opener, aprikalim. J Thorac Cardiovasc Surg. 1995;110:1083-95.

12. Cohen NM, Wise RM, Wechsler AS, Damiano RJ. Elective cardiac arrest with a hyperpolarizing adenosine triphosphate-sensitive potassium opener. A novel form of myocardial protection? J Thorac Cardiovasc Surg. 1993;106:317-28.

13. Jayawant AM, Lawton JS, Hsia P-W, Damiano RJ. Hyperpolarized cardioplegic arrest with nicorandil. Advantages over other potassium channel openers. Circulation. 1997;96(suppl II):II240-6.

14. Pignac J, Bourgouin J, Dumont L. Cold cardioplegia and the $\mathrm{K}^{+}$ channel modulator aprikalim (RP 52891): improved cardioprotection in isolated ischemic rabbit hearts. Can J Physiol Pharmacol. 1994;72: 126-32.

15. Jayawant AM, Stephenson ER, Damiano RJ. Advantages of continuous hyperpolarized arrest with pinacidil over St. Thomas' Hospital solution during prolonged ischemia. J Thorac Cardiovasc Surg. 1998; 116:131-8.

16. Grover GJ. Protective effects of ATP-sensitive potassium-channel openers in experimental myocardial ischemia. J Cardiovasc Pharmacol. 1994;24(suppl):S18-27.

17. Quast U, Guillon JM, Cavero I. Cellular pharmacology of potassium channel openers in vascular smooth muscle. Cardiovasc Res. 1994;28: 805-10.

18. Vanhoutte PM. Old-timer makes a comeback. Nature. 1998;396:213.

19. Ge ZD, Zhang XH, Fung PCH, He GW. Endothelium-dependent hyperpolarization and relaxation resistant to NG-nitro-L-arginine and indomethacin in coronary circulation. Cardiovasc Res. 2000;46:54756.

20. He G-W, Yang C-Q, Graier WF, Yang J-A. Hyperkalemia alters EDHF-mediated hyperpolarization and relaxation in porcine coronary arteries. Am J Physiol Heart Circ Physiol. 1996;271:H760-7.

21. Yang Q, Ge Z-D, Yang C-Q, Huang H, He G-W. Bioassay of endothelium-derived hyperpolarizing factor with abolishment of nitric oxide and the role of gap junctions in the porcine coronary circulation. Drug Dev Res. 2003;58:99-110.

22. Ignarro LJ, Burke TM, Wood KS, Wolin KS, Kadowitz PJ. Association between cyclic GMP accumulation and acetylcholine-elicited relaxation of bovine intrapulmonary artery. J Pharmacol Exp Ther. 1984;228:682-90.

23. He G-W, Buxton BF, Rosenfeldt FL, Wilson AC, Angus JA. Weak $\beta$-adrenoceptor mediated relaxation in human internal mammary artery. J Thorac Cardiovasc Surg. 1989;97:259-66.

24. Ge Z-D, He G-W. Comparison of University of Wisconsin and St. Thomas' Hospital solutions on endothelium-derived hyperpolarizing factor-mediated function in coronary micro-arteries. Transplantation. 2000;70:22-31.

25. Wilde AAM, Kléber AG. The combined effects of hypoxia, high $\mathrm{K}^{+}$, and acidosis on the intracellular sodium activity and resting potential in guinea pig papillary muscle. Circ Res. 1986;58:249-56.

26. Reimer KA, Jennings RB. Myocardial ischemia, hypoxia, and infarction. In: Fozzard HA, Haber E, Jennings RB, Katz AM, Morgan HE, editors. The heart and cardiovascular system. New York: Raven; 1992. p. 1973-5.

27. Ren Z, Yang Q, Floten HS, He G-W. Hypoxic preconditioning in coronary microarteries: role of EDHF and $\mathrm{K}+$ channel openers. Ann Thorac Surg. 2002;74:143-8.

28. Ibbotson T, Edwards G, Noack T, Weston AH. Effects of P1060 and aprikalim on whole-cell currents in rat portal vein; inhibition by glibenclamide and phentolamine. Br J Pharmacol. 1993;108:991-8.

29. Noma A. ATP-regulated $\mathrm{K}^{+}$channels in cardiac muscle. Nature. 1983;305:147-8. 